\title{
Evaluation of Adblock Software Usage
}

\author{
Anna Sołtysik-Piorunkiewicz ${ }^{*}$, Artur Strzelecki, and Edyta Abramek \\ Department of Informatics, University of Economics in Katowice, \\ Katowice, 40-287, Poland \\ anna.soltysik-piorunkiewicz@ue.katowice.pl, artur.strzelecki@ue.katowice.pl, \\ edyta.abramek@ue.katowice.pl
}

\begin{abstract}
The article shows the main factors of adblocking software usage. The study was based on data obtained by a web questionnaire. The research was focused on evaluation of ad blocking (adblock) software usage factors in five categories: (1) gender, age, and education; (2) use of advertising and sources of knowledge about advertising; (3) technical and social reasons for blocking online advertisements; (4) usage of an adblock-wall; and (5) type of online advertisement. An evaluation of adblock usage factors revealed four main technical reasons for adblock usage connected with website technology and web development problems - interruption, amount of ads, speed, and security; and one social reason for adblock usage, namely, the problem of privacy.
\end{abstract}

Keywords: Adblock Software, Web Advertisement, Website, Security, Privacy.

\section{Introduction}

Nowadays the role of online marketing tools is increasing in e-business. Describing the ad blocking software usage factors for future web advertisement strategy development is an important issue in the context of online marketing tool effectiveness. The changes in online advertisements, i.e. native advertisements and new versions of old "conventional advertisements," depend on the behavior of internet users, especially the marketing strategy of targeting users in e-business. This article is the result of research study that was performed using the following methodology:

1. Selecting a research problem, research aims and research questions.

a. Formulating a research thesis.

b. Analyzing literature on the subject of ad blocking software usage.

2. Conducting further study using Statistica 13.1 software tools.

a. Qualitative and quantitative research.

b. Graphical reports of data analysis.

\footnotetext{
* Corresponding author
}

(C) 2019 Anna Sołtysik-Piorunkiewicz et al. This is an open access article licensed under the Creative Commons Attribution License (http://creativecommons.org/licenses/by/4.0).

Reference: A. Sołtysik-Piorunkiewicz, A. Strzelecki, and E. Abramek, "Evaluation of Adblock Software Usage," Complex Systems Informatics and Modeling Quarterly, CSIMQ, no. 21, pp. 51-63, 2019. Available: https://doi.org/10.7250/csimq.201921.04

Additional information. Author ORCID iD: A. Sołtysik-Piorunkiewicz - https://orcid.org/0000-0002-7935-1377, A. Strzelecki https://orcid.org/0000-0003-3487-0971, and E. Abramek - https://orcid.org/0000-0002-8517-424X. PII S225599221900124X. Received: 30 October 2019. Accepted: 18 December 2019. Available online: 31 December 2019. 
3. Amalgamating research findings.

a. Conclusions from the research study.

b. Indicating the limitations of the research carried out.

c. Conditions for further research.

The article is divided into six Sections. Section 1 introduces the article. Section 2 is devoted to the literature review of ad blocking of online advertisements and discussing approaches to blocking advertisements and internet behaviors from different users' points of view. Section 3 characterizes reasons for ad blocking software usage for blocking advertisements on the internet. Section 4 describes the research methodology in terms of research goals and tasks. Section 5 presents the results of the study. Section 6 concludes the paper with a summary of main findings.

\section{Literature Review}

Referring to the report [1], Poland is one of the leading countries where internet advertisements are often blocked by users using ad blocking software. The phenomenon is not conducive to the development of the electronic business of companies that earn money by displaying ads. The perspective of charging instead of advertising is not beneficial either for publishers or for content recipients. Therefore, changes in the sustainable advertising market are necessary. However, to enter them, it is necessary to thoroughly understand the recipients of the ads, their reaction to the ads and expectations related to the ads.

The most popular forms of online advertisements are banners, which are referred to as "conventional advertisements". They consist in placing graphic elements of various forms and sizes on a website. The elements redirect the interested party to the advertiser's website. Such a form of advertising allows a company to establish its online presence and enhance its image. Static banners are commonly considered the least invasive ads. In contrast, the most aggressive form of advertising is sound ads. An interesting type of advertising is the so-called native ads. Native advertising, cleverly woven into some content, e.g. an article, is usually not treated by the recipient as an invasive advertisement. It has therefore become popular among publishers.

In order to block advertising on a website, users use software called adblock. The term adblock refers to software for blocking online advertisements. There are four different types of web browser plugins [2], [3] which currently are popular and block advertisements: AdBlock, AdBlock Plus, uBlock and uBlock Origin. uBlock is considered as the plugin with the best performance, in terms of ad and third party tracker filtering, and least privacy tracking [4].

On the other hand, there is so called non-intrusive advertising [5]. Examples of non-intrusive advertisements are advertisements in search engine search results. The advertisements appear only after a user enters a query in the search engine and receives the results. Additionally there is a comparative study report of online software and hardware ad blockers, in particular on AdBlock, AdBlock Plus, and AdTrap [6]. Research shows that AdBlock is ahead of the others in terms of ad blocking ability.

\subsection{User Activity in Adblock Usage}

In 2016, a study made on 2 million panelists revealed that $18 \%$ of US users were using ad blocking software, whereas in Germany and United Kingdom it was already 37\% [7].

The filtering performance of both AdBlock and AdBlock Plus software was compared. Comparison was based on using the percentage of ad requests blocked when accessing a web page out of the total number of page requests, as well as web page loading time, as two specific metrics for comparison. AdBlock surpasses AdBlock Plus in terms of ad filtering capability, and the difference between those two tools is mainly due to different default filter lists that they use [8]. 
Since more and more web traffic runs through mobile devices, more recent studies are on mobile ad blockers. Comparison of 97 ad blocking mobile apps extracted from Google Play showed surprising results. While the main (declared) purpose of the apps is to block advertisements and mobile tracking services, data analysis revealed the paradoxical presence of third-party tracking libraries and permissions to access sensitive resources on users' mobile devices, as well as the existence of embedded malware code within some mobile ad blockers [9].

Ad blocking systems rely on crowdsourcing help in terms of creating filtering lists. Analysis of crowdsourcing actions shows that often there are false positive errors, i.e. blocking legitimate content and there are attacks from ad publishers against ad blockers [10]. Millions of web users rely on filter lists to protect their privacy and improve their browsing experience. Filter lists are maintained by a small number of contributors, who use a variety of undocumented heuristics to determine what rules should be included [11]. Other comparisons of online ad blocking lists revealed that blacklists can be reactive or proactive in tackling the online ad and tracking services [12].

There are some enterprise network environment solutions for DNS Adblock, which block advertisement requests on the internet connection level. They reduce traffic and bandwidth utilization [13]. Ad blocking is often analyzed in terms of digital advertising, privacy preserving, ad effect measurement and ad fraud [14].

Recently an Adgraph tool was presented which creates a graph representation of the HTML structure, network requests, and JavaScript behavior of a webpage, and, using this unique representation, trains a classifier for identifying advertising and tracking resources [15].

Nowadays, internet users are more and more resistant to different forms of advertisements. Users have become better prepared for receiving internet promotion of products and services. They seem to be better focused on reviewing certain criteria of advertisements, i.e. location, contrast and size of the advertising unit [16], than during the initial period of internet development. The advertisements' forms are still very popular but no longer as efficient as they used to be.

In the users' opinion, they express strong negative sentiment on ads and moderate positive sentiment if it is possible for them to subscribe to an ad-free fee-financed website [17]. Adoption of ad blockers by users is positively influenced by the level of knowledge of their advantageous features [18].

\subsection{Website Owners Preventing Ad Blocking}

Some descriptions of cases are characterized on the internet by the users [19] in the context of website publishers preventing them from blocking advertisements [20]. One prevention option is based on legal regulations and the right to maintain the integrity of the website publisher's work, or the right not to allow the ad blocking, because it may be viewed as a change to the content and form of the website publisher's work [21], [22]. Another option is based on the intention of the publisher to establish cooperation with creators of software for blocking advertisements [23] and to create advertisements which users are unable to filter with blocking software [24].

Nowadays, programming techniques allow detecting mechanisms for blocking advertisements very effectively, and then prevent access to the website when ad blocking software is active and set to block advertisements [25], [26]. With blocking ads, it is possible to effectively fight at the technology level [27]. Mastering the phenomenon at the social level is not so easy. Companies that offer content on the internet understand that users cannot resort to the simplest method, i.e. a total ban on access to content, because they will look for content on other, free websites [28]. Therefore, a better solution is to deliver ads in a form adapted to the expectations of internet users. A surfer should be able to decide and choose how he/she wants to receive advertisements. According to the report [1], it is the methods of and approaches to making advertisements available to them that users of websites are opposed to. It is therefore necessary to create IT solutions that will reconcile the expectations of publishers and users blocking advertisements. 
It is observed that there is a clash between ad blockers and anti ad blockers. An automated machine learning based approach is proposed to identify anti ad blockers that detect and react to ad blocking software users [29]. The goal is to enable ad blockers to bypass state-of-the-art anti ad blockers [30].

To determine the opportunities for website owners to effectively deal with users' ad blocking activity, there are propositions to look at the types of advertisements being targeted and reactions to adblock detecting. If the publishers detect the ad blocker being turned on, they generally try to (1) educate the users (2) persuade them, (3) propose a special offer or (4) threaten to take action on the issue [31].

Another study documents how advertising and analytics companies have used web sockets to bypass ad blocking, exfiltrate user tracking data, and deliver advertisements. Until April 2017 they monitored a bug in Google Chrome which was preventing ad blocking software from working [32].

Ad blocking software threatens the revenue of many websites and raises fears about the viability of digital advertising as a whole. Which factors help the unblocking or whitelisting of selected websites remains largely unknown. User tests to determine whether banner appeals can reduce ad blocking show that these appeals reduce ad blocking by $1 \%$ of the ad blocking software users, and among frequent visitors who encounter repeated banner appeals, this percentage increases to $2 \%$ [33].

To fight the economic costs of the ad blocking phenomenon, the group of giants including Google, Facebook, Microsoft, P\&G, Unilever, Thomson Reuters, the World Federation of Advertisers (WFA) and the Interactive Advertising Bureau (IAB) formed an alliance named Coalition for Better Ads; including marketers, publishers and agencies worldwide. They suggest limits of ad format intrusiveness to be implemented worldwide by means of self-regulation [34].

\subsection{Other Outcomes by Using Adblock Software}

Adblockers are popular solutions in order to increase web privacy. By enabling ad blocking software, not only advertisements, but also many tracking scripts for tracking user activities, are blocked. Results show significant differences among adblockers regarding their filtering performance as affected by the applied configurations of adblockers and filtering lists [35]. Adblockers are often considered as web privacy tools that block third-party advertising. They are very effective at reducing third-party tracking [36]. Third party tracking scripts are classified into such categories as: ad trackers, analytics, beacons, social, and widgets [37].

Some propositions suggest that users should be charged for using ad blocking software to maintain the balance between advertisers and users, since this kind of software acts as an intermediary platform [38]. Some researchers have designed systems for smart advertisement blocking. For instance, such systems can protect users' privacy and preserve online advertising business [39].

Ad blocking has a positive impact on user engagement with the Web. Firefox has revealed that two groups were tested: one using adblocks, the other one not using them. For the first group, there were increases in both active time spent in the browser and the number of pages viewed, while seeing no change in the number of searches [40].

\section{Reasons for Usage of Adblock Software}

There are different reasons connected to blocking web advertisements. The research shows that the users' preference for privacy of their data and confidentiality of their online activities is the most important factor [35], and, for this reason, personalized advertisements are perceived as a threat, and the use of advertisements in a way that is unknown to the user can be the source of a risk of additional costs (using data transmission packages); so that is the main reason why they are simply blocked by users [36], [37]. Therefore, it is necessary to find the proper strategy, 
based on investigated reasons, to stop blocking advertisements, in order to make the development of e-business sustainable.

Exploring the reasons for blocking online advertising is exploring a complex topic [17], [18]. The topic of advertisement blocking should be considered from multiple perspectives. The last PageFair-2017 report showed [1], that the main reasons for blocking advertisements using ad blocking software were [19]: security, interruption, speed, too many ads, privacy, poor frequency camping, and others. Comparing user gender, women usually mentioned that they were afraid of viruses and malware, and men claimed that the greatest nuisance was the interference of advertising in continuous browsing of online content. There is more than one reason for blocking the advertisements. Over $70 \%$ of respondents chose more than one reason as "the most important one" in connection with their use of ad blocking software.

Users do not mind advertisements as such, but they are bothered rather by their aggressive form, such as a sudden sound or an advertisement suddenly covering the browsed content and, additionally, the advertisement not allowing itself to be skipped or closed.

The PageFair report's index of blocking ads for Poland in 2017 [1] amounted to 33\%, while in 2015 it maintained the level of $34.9 \%$. Another study published in 2018 showed that $61.2 \%$ of Polish internet users are using ad blocking software [41]. Apparently, the reason for this phenomenon is the overload with advertisements. Greece, Poland, Germany and Sweden are the countries in Europe where the most ads are blocked. According to the PageFair report from 2017, Internet users blocked ads mainly due to: (1) security, (2) interruption by ads of various types of content, (3) slow loading of web pages and inconveniences connected with it, e.g. nuisance and excess ads that pop up at any time, from all directions, and still run sounds, etc. Our own research was slightly different from the PageFair survey [42]. According to our research, users are most disturbed by: (1) advertising interruption of various web content, (2) a large number of ads (excess advertising) and (3) slow page loading (speed).

\section{Research Methodology of Adblock Software Usage Factors}

The main research goal was focused on describing the ad blocking software usage factors for future web advertisement strategy development. Research study was started after preliminary research on types of online advertisement, and the diversity of ad blocking reasons and methods were characterized [3]. The new classification of ad blocking reasons was developed, based on previous studies and literature reviews [3], [42]. The study of classification included the technical and social reasons for ad blocking as well (Figure 1).

After the classification study, the following research questions were proposed to fulfill the research goals:

RQ1: Who is using the adblock software?

RQ2: What are the main reasons for blocking the online advertisements?

RQ3: What types of online advertisements are acceptable for users?

RQ4: Who is using the ad block-wall software?

RQ5: What is the correlation between the type of online advertisement and the usage of ad blocking software?

In order to recognize the activity of users of computer programs blocking the content of online advertisements, an electronic questionnaire was developed to discover the main factors for adblocking software usage. The study was conducted in 2017. The target group of the study included people of different ages. In total, responses were collected from 774 respondents. The results are characterized by the following factors in five categories [42]:

- Gender, age, and education.

- Technical and social reasons for blocking online advertisements.

- Use of advertising and sources of knowledge about advertising. 
- Adblock-wall.

- Type of online advertisement.

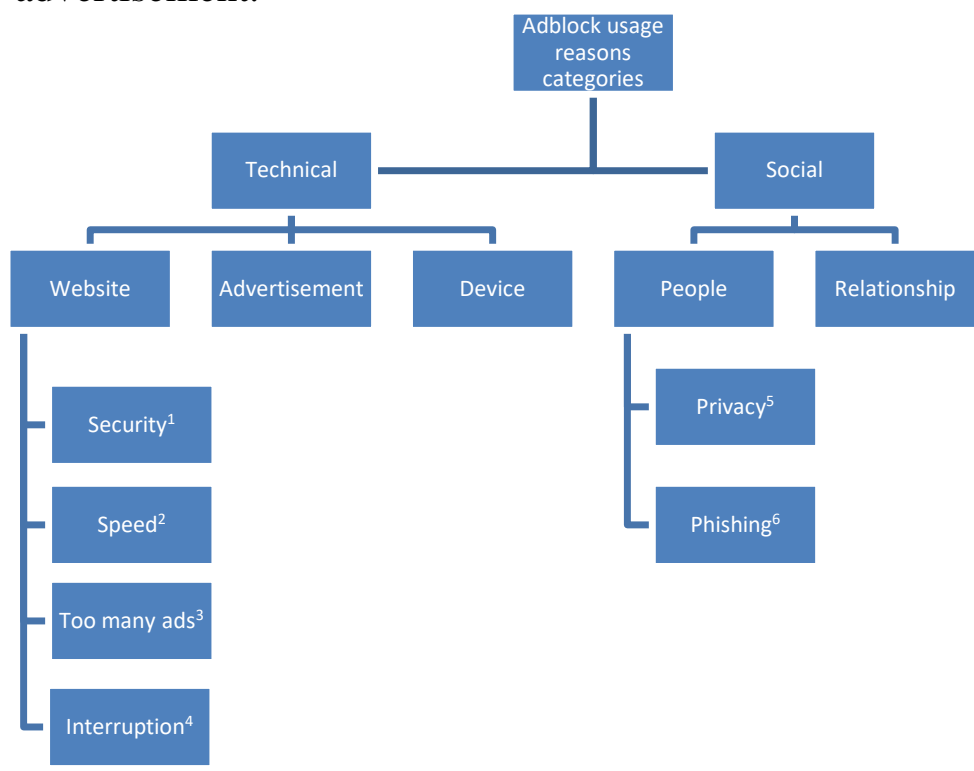

Note: (1) virus and malware, (2) slow website loading, (3) too many ads, (4) interrupting ads with read content, (5) privacy protection, (6) phishing protection.

Figure 1. Main categories of adblock usage reasons classification. Source: Own study [42].

\section{Study Results and Research Findings for Adblock Software Usage}

\subsection{Gender, Age, and Education vs. Usage of Adblock Software}

Most of the respondents were men, i.e. 56.1\%. The men are blocking the advertisements more often than women. There were $55.3 \%$ of higher education graduates in the group of people who completed the survey. Those with secondary education accounted for $44.5 \%$. There were also people with vocational education (Figure 2).

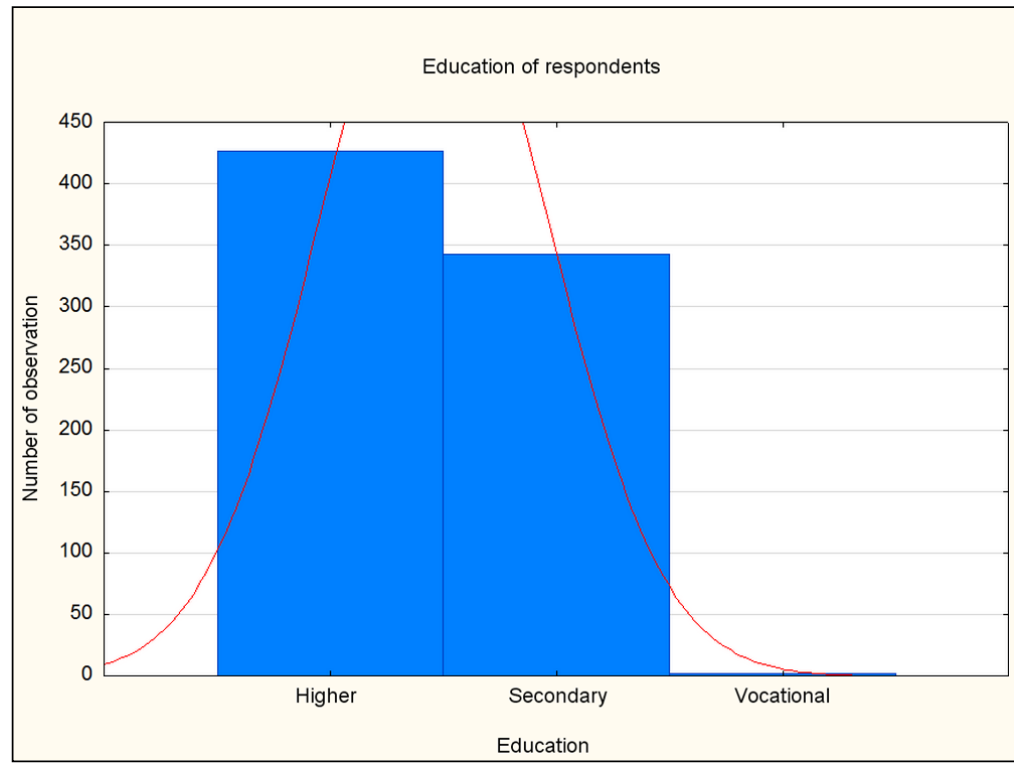

Figure 2. Educational structure of respondents $(\mathrm{N}=774)$. Source: Own study with the use of the Statistica 13.1 . 
The largest age group was formed by respondents in the age range of 18-24 (Table 1) and, as it turns out, these respondents most often block advertisements.

Table 1. Blocking of ads divided into age groups

\begin{tabular}{|c|c|c|c|c|c|}
\hline Age group & $\begin{array}{c}\text { Number of } \\
\text { respondents }\end{array}$ & $\begin{array}{c}\text { Percentage of } \\
\text { respondents }\end{array}$ & $\begin{array}{c}\text { Using ad } \\
\text { blocking } \\
\text { software }\end{array}$ & $\begin{array}{c}\text { Not using ad } \\
\text { blocking } \\
\text { software }\end{array}$ & $\begin{array}{c}\text { Using ad blocking } \\
\text { software - I do not } \\
\text { know, what is this? }\end{array}$ \\
\hline $18-24$ & 436 & $56.33 \%$ & $45.22 \%$ & $9.56 \%$ & $1.55 \%$ \\
\hline $25-34$ & 254 & $32.80 \%$ & $24.81 \%$ & $7.88 \%$ & $0.13 \%$ \\
\hline $35-44$ & 70 & $9.04 \%$ & $6.20 \%$ & $2.84 \%$ & $0.00 \%$ \\
\hline $45-54$ & 11 & $1.42 \%$ & $0.39 \%$ & $1.03 \%$ & $0.00 \%$ \\
\hline $55-64$ & 2 & $0.26 \%$ & $0.26 \%$ & $0.00 \%$ & $0.00 \%$ \\
\hline $65+$ & 1 & $0.15 \%$ & $0.13 \%$ & $0.00 \%$ & $0.00 \%$ \\
\hline Summary & $(774)$ & $100.00 \%$ & $\begin{array}{c}77.00 \% \\
(596)\end{array}$ & $\begin{array}{c}21.32 \% \\
(165)\end{array}$ & $\begin{array}{c}1.68 \% \\
(13)\end{array}$ \\
\hline
\end{tabular}

$77 \%$ of respondents admitted that they use software to block online advertisements (Table 2). There are also internet users who do not use adblocks $(21.32 \%)$ or do not know about the existence of ad blocking software (1.68\%).

Table 2. The respondents' diversity of using ad blocking software

\begin{tabular}{|l|c|c|}
\hline \multicolumn{1}{|c|}{ The respondents' diversity } & Number of respondents & $\begin{array}{c}\text { Percentage of } \\
\text { respondents }\end{array}$ \\
\hline Respondents who use the ad blocking software & 596 & $77.00 \%$ \\
\hline $\begin{array}{l}\text { Respondents who do not use the ad blocking } \\
\text { software }\end{array}$ & 165 & $21.32 \%$ \\
\hline $\begin{array}{l}\text { Respondents who do not know about the } \\
\text { adblocks }\end{array}$ & 13 & $1.68 \%$ \\
\hline Summary & 774 & $100.00 \%$ \\
\hline
\end{tabular}

\subsection{Technical and Social Reasons for Blocking Online Advertisements}

The respondents had learned about the possibility of blocking advertisements in the following ways: from friends $(31.5 \%)$, from the internet $(22.7 \%)$, from the browser settings $(8.7 \%)$. At the same time, $35.4 \%$ of respondents did not remember where they found out about ad blocking software.

The results presented further concern only people who used ad blocking software, i.e. 596 respondents (out of 774). Each of the 596 respondents (100\%) had ad blocking software installed on a desktop computer, 99 respondents $(16.6 \%)$ - on a smartphone, and 54 respondents $(9.1 \%)$ on a tablet. Most respondents, i.e. 400 (67.1\%) used the default ad blocking settings, and the rest of the respondents had configured the software according to their needs. Out of 596 respondents, only $77(12.9 \%)$ did not exclude this program. Most respondents, i.e. $519(87.1 \%)$ actively disabled the adblocks to gain access to blocked content.

There are at least two reasons why users of content blockers temporarily disable them:

- firstly, there is a need to temporarily use content that is unavailable or invisible due to ad blocking activity (301 respondents, 58\%);

- secondly, it is about permanently turning off an adblock for a selected website or adding that website to the list of exceptions (218 people, $42 \%$ ).

If we divide the group of respondents by gender, it turns out that all males know what an adblock is and either use it $(78.3 \%)$ or not. Among females, 13 respondents answered that they did not know what an adblock was. Within that group, i.e. all female respondents, $75.2 \%$ use ad blocking software. 
When it comes to using ad blocking software and the education of the respondents, both the group with secondary and higher education have the same percentage of ad blocking software users (78.3\%). Further analysis will consist of more detailed presentation of the results in the two most widely represented age groups who use adblocks. Everyone uses ad blocking software on their ordinary computers. Interestingly enough, within the 25-34 age group, it is more frequently installed on smartphones and tablets as well $-17.7 \%$ and $12.5 \%$ respectively, and within the 18 24 age group the numbers are $-14.6 \%$ and $4.5 \%$. Despite the fact that the 18-24 age group is most widely represented in the research, using ad blocking software on mobile devices is less widespread here than in the 25-34 age group.

With respect to configuring adblock software on their own, the group aged 25-34 also demonstrates greater activity (38\% defined the way ad blocking software functions on their own, and in the younger group the percentage is $28 \%$ ).

Both groups behave in a similar way with respect to switching off the adblock software. The respondents aged between 18-24 declared that $88.2 \%$ of them switch off the adblock software and, within the group aged $25-34$, the procedure is followed by $88.5 \%$ of adblock users.

Both groups responded similarly to the question: why they switch off the adblock software. $59.7 \%$ of respondents aged 18-24 temporarily switch off the adblock software in order to access the content and then switch it on again, while within the group aged 25-34, the procedure is followed by $57.9 \%$ of respondents.

After encountering an ad block-wall (see Section 5.4 for details), the majority of respondents (517 people, 55.5\%) disabled adblocks, or added a website to exceptions and used its content.

\subsection{Use of Advertising and Sources of Knowledge about Advertising}

As a result of the research, it was determined which type of advertising causes the greatest rejection by the recipients. Respondents, asked about which forms of advertising they accept or which they do not accept, provided the answers presented in Table 3. 77.20\% of users accepted static graphic or text banners, instead of video ads (51.80\%), and native ads (63.65\%). Audio ads were mostly seen as not acceptable (99.00\%).

Table 3 presents the structure of acceptable and not acceptable advertisement types: static graphic or text banner, native, audio, video skippable and video not skippable ads.

Table 3. User-preferred types of ads

\begin{tabular}{|l|c|c|}
\hline Type of advertisement & I accept & I do not accept \\
\hline Static graphic or text banners & $77.20 \%$ & $22.80 \%$ \\
\hline Video ads - skippable & $48.20 \%$ & $51.80 \%$ \\
\hline Native ads & $36.35 \%$ & $63.65 \%$ \\
\hline Audio ads & $1.00 \%$ & $99.00 \%$ \\
\hline Video ads - not possible to omit them & $3.90 \%$ & $96.10 \%$ \\
\hline
\end{tabular}

\subsection{Adblock-wall}

The users' behavior changes when the respondents considered ad block-wall usage. $81.9 \%$ of respondents aged 18-24 clash with this type of blockade while browsing websites with adblocks switched on. Even more respondents, i.e. 93.2\% within the group aged 25-34, reported the clash with this type of blockade before accessing the content.

Within the group aged 18-24, after clashing with the blockade, only $19.73 \%$ of the respondents left the website, and $35.59 \%$ switched off the ad blocking software and accessed the content that was not available before. With the group aged 25-34, the division is different - only $17.21 \%$ of the respondents, when clashing with the blockade, left the website and the remainder 
of the respondents, after clashing with the blockade, decided to switch off the ad blocking software.

According to the survey results, about $60 \%$ of the surveyed users aged $18-24$ block ads:

- Age group 18-24: 56.30\% of internet users block internet advertising,

- Age group 25-34: 32.80\% of internet users block internet advertising,

- Age group 35-44: 9\% of internet users block internet advertising.

The older users are blocking the unwanted content less often than younger users. Respondents aged 18-24 declared that in $88.2 \%$ of occurrences they excluded adblock software to gain access to content, and in the group of people aged 25-34-88.5\% of users disabled the ad block software. Both groups of respondents react similarly to blocking advertisements. After the collision with an adblock-wall, in the group of $18-24 \%$ up to $35.4 \%$ of the respondents would leave the website, and in the group of 25-34 years, as many as $49.7 \%$ of the respondents would leave the website. Other respondents (constituting the majority) decide to disable the blockade to access the content.

\subsection{Technical and Social Reasons for Ad Blocking vs. Age and Education}

Table 4 presents the main reasons for blocking advertisements, taking into account two categories: technological reasons - specific for the website for advertising and the type of device, and social reasons - specific for users of websites [42].

Table 4. The technical and social reasons of ads blocking grouped by categories based on [42].

\begin{tabular}{|c|c|c|c|}
\hline \multicolumn{2}{|c|}{ Main categories of reasons } & \multirow{2}{*}{$\begin{array}{l}\text { The reasons for blocking ads by users } \\
\text { Security (Virus and malware protection) }\end{array}$} & \multirow{2}{*}{$\frac{\text { \% Index }}{2.50 \%}$} \\
\hline \multirow{11}{*}{ Technical } & \multirow{4}{*}{ Website } & & \\
\hline & & Slowly loading website & $3.50 \%$ \\
\hline & & Slowed down web browser & $0.00 \%$ \\
\hline & & Interruption - content interrupted by ads & $50.30 \%$ \\
\hline & \multirow{6}{*}{ Advertisement } & Use of interactive advertising & $0.00 \%$ \\
\hline & & Too many ads on the website & $37.80 \%$ \\
\hline & & Advertising takes up the whole screen, & $0.00 \%$ \\
\hline & & $\begin{array}{l}\text { Automatic, suddenly playing sound, difficult closing advertising - } \\
\text { the X button can't be found, overlay other content by advertising }\end{array}$ & $0.00 \%$ \\
\hline & & Obstruction in receiving content & $0.00 \%$ \\
\hline & & No ability to filter ads & $0.00 \%$ \\
\hline & $\begin{array}{l}\text { Device (computer, } \\
\text { smartphone, tablet) }\end{array}$ & $\begin{array}{l}\text { Transfer fees on mobile devices, need to increase internet link } \\
\text { bandwidth to play ads }\end{array}$ & $0.00 \%$ \\
\hline \multirow{3}{*}{ Social } & \multirow{3}{*}{$\begin{array}{l}\text { People and } \\
\text { relationships } \\
\text { (website-user) }\end{array}$} & Privacy protection & $1.70 \%$ \\
\hline & & Phishing protection & $0.00 \%$ \\
\hline & & Protection against tracking by unknown sites & $0.00 \%$ \\
\hline Others & - & - & $4.20 \%$ \\
\hline
\end{tabular}

Table 5 shows the most important reasons, why users in different age groups are blocking the advertisements.

Table 5. Motivation of adblock usage vs. age, based on [42].

\begin{tabular}{|l|c|c|c|c|r|r|}
\hline \multicolumn{1}{|c|}{$\begin{array}{c}\text { Motivation of ad blocking } \\
\text { software usage }\end{array}$} & $\begin{array}{c}\text { Age 18- } \\
\mathbf{2 4}\end{array}$ & $\begin{array}{c}\text { Age 25- } \\
\mathbf{3 4}\end{array}$ & $\begin{array}{c}\text { Age 35- } \\
\mathbf{4 4}\end{array}$ & $\begin{array}{c}\text { Age 45- } \\
\mathbf{5 4}\end{array}$ & Age 55-64 & Age 65+ \\
\hline Interruption & $58,00 \%$ & $33,33 \%$ & $8,00 \%$ & $0,67 \%$ & $0,00 \%$ & $0,00 \%$ \\
\hline Too many ads on the websites & $61,78 \%$ & $30,67 \%$ & $6,67 \%$ & $0,44 \%$ & $0,44 \%$ & $0,00 \%$ \\
\hline Slowly loading websites & $47,62 \%$ & $28,57 \%$ & $23,81 \%$ & $0,00 \%$ & $0,00 \%$ & $0,00 \%$ \\
\hline Security (viruses and malware) & $66,67 \%$ & $20,00 \%$ & $6,61 \%$ & $0,00 \%$ & $6,67 \%$ & $0,00 \%$ \\
\hline Privacy & $60 \%$ & $40,00 \%$ & $0,00 \%$ & $0,00 \%$ & $0,00 \%$ & $0,00 \%$ \\
\hline
\end{tabular}


Table 6 shows the most important reasons of blocking the advertisements in different groups of education.

Table 6. Motivation of adblock usage vs. education. Source: Own authors based on [42].

\begin{tabular}{|l|c|c|c|}
\hline $\begin{array}{c}\text { Motivation of ad blocking } \\
\text { software usage }\end{array}$ & Higher education & Secondary education & Vocational education \\
\hline Interruption & $54,85 \%$ & $45,15 \%$ & $0,00 \%$ \\
\hline $\begin{array}{l}\text { Too many ads on the } \\
\text { websites }\end{array}$ & $52,68 \%$ & $46,43 \%$ & $0,89 \%$ \\
\hline Slowly loading websites & $38,10 \%$ & $61,90 \%$ & $0,00 \%$ \\
\hline $\begin{array}{l}\text { Security (viruses and } \\
\text { malware) }\end{array}$ & $73,33 \%$ & $26,67 \%$ & $0,00 \%$ \\
\hline Privacy & $60,00 \%$ & $40,00 \%$ & $0,00 \%$ \\
\hline
\end{tabular}

\section{Conclusions}

The results and research findings show the reasons of ad blocking and help to reveal basic recommendations regarding ad publishing on websites. The forms of accepted advertising were discovered.

The main technical reasons for ad blocking software usage are:

- too often displaying advertisements (50.30\% of internet users complain about that factor),

- excess advertising on the web (37.80\% of internet users complain about that factor),

- slowly loading websites (3.50\% of internet users complain about that factor),

- virus and malware protection (2.50\% of internet users complain about that factor).

The main social reason for ad blocking software usage is connected with privacy protection of users and their relationship with website in human-computer interaction.

As has already been mentioned, Poland is at the forefront of countries that block advertisements. This study shows that the biggest problems for internet users are successively: interruption (50.30\%), too many ads $(37.80 \%)$, speed $(3.50 \%)$, and security $(2.50 \%)$. For comparison, the results of the PageFair-2017 report differ. The main reasons for blocking ads according to the said report were successively: security, interruption, speed, too many ads and privacy.

The results of the research show that internet users block advertisements because they defend themselves against their effects, e.g. because they interfere with the reception of content or are a source of malware. Adblock extensions have thus become a panacea for users of unwanted content [43]. Growing dissatisfaction of internet users with advertisements shows a lack of knowledge of publishers about methodologies or ways of making advertisements available, i.e. directing them to so-called "matching users" [44]. Advertisements are currently often being displayed, i.e. directed, to random recipients, which causes understandable dissatisfaction of internet users. Only the advertisement tailored to the user will not be a problem for him/her and will not force him/her to use the software blocking unwanted ads.

It is therefore required to match ads to recipients. Solutions in this direction are already being proposed - affiliate programs that include the publisher, advertiser and customers or the publisher, advertiser, customers and owner of the affiliate program. Such a solution ensures that each participant wins: the publisher attracts the right customers and thus obtains measurable financial benefits, the customers receive matching advertising content, and the advertiser pays for specific actions performed by matching customers. What is worth emphasizing is that the affiliate program allows the publisher to have control over the form of advertising (banner, mailing, or the entire website), and over the customers who receive the advertisements. At this stage, this solution seems to be the best, which limits the use of adblock extensions that block advertisements and at the same time emphasizes the benefits of partners' cooperation for a sustainable advertising market [45]. 
There are some limitations of this research study. One, the most important, research issue for the future should be the economic and organizational aspects of the problem of ad blocking software usage in e-business development, especially for e-marketing strategy based on social media platforms development, and e-customer relational management strategy with e-commerce platforms. The technical and social advertisement issues should be developed in case of the different internet users: e-client, e-business owner, including marketers, publishers, and content providers.

\section{References}

[1] "The state of the blocked web"- PageFair 2017 Adblock Report, 2017.

[2] W. Rens, "Browser forensics: adblocker extensions," 2017.

[3] A. Strzelecki, E. Abramek, and A. Sołtysik-Piorunkiewicz, "Adblock Usage in Web Advertisement in Poland," Advances in Intelligent Systems and Computing, vol. 887, K. Arai, S. Kapoor, and R. Bhatia, Eds. Springer, pp. 13-23, 2019. Available: https://doi.org/10.1007/978-3-030-03405-4_2

[4] K. Garimella, O. Kostakis, and M. Mathioudakis, "Ad-blocking: A Study on Performance, Privacy and Counter-measures," Proceedings of the 2017 ACM on Web Science Conference - WebSci '17, pp. 259-262, 2017. Available: https://doi.org/10.1145/3091478.3091514

[5] W. Q. Ming and R. Yazdanifard, "Native Advertising and its Effects on Online Advertising," Glob. J. HumanSocial Sci. E Econ., vol. 14, no. 8, pp. 11-14, 2014.

[6] E. L. Post and C. N. Sekharan, "Comparative Study and Evaluation of Online Ad-Blockers," Proceedings of the 2nd International Conference on Information Science and Security (ICISS), pp. 1-4, 2015. Available: https://doi.org/10.1109/ICISSEC.2015.7370988

[7] M. Malloy, M. McNamara, A. Cahn, and P. Barford, "Ad Blockers: Global Prevalence and Impact," Proceedings of the 2016 ACM on Internet Measurement Conference - IMC '16, pp. 119-125, 2016. Available: https://doi.org/10.1145/2987443.2987460

[8] J. Huang and W. Cheng, "Filtering performance analysis and application study of advertising filtering tools," Proceedings of the 12th International Conference on Intelligent Systems and Knowledge Engineering (ISKE), pp. 1-5, 2017. Available: https://doi.org/10.1109/ISKE.2017.8258716

[9] M. Ikram and M. A. Kaafar, "A First Look at Mobile Ad-Blocking Apps," Proceedings of the IEEE 16th International Symposium on Network Computing and Applications (NCA), pp. 1-8, 2017. Available: https://doi.org/10.1109/NCA.2017.8171376

[10] M. Alrizah, S. Zhu, X. Xing, and G. Wang, "Errors, Misunderstandings, and Attacks," Proceedings of the Internet Measurement Conference on - IMC '19, pp. 230-244, 2019. Available: https://doi.org/10.1145/3355369.3355588

[11] A. Vastel, P. Snyder, and B. Livshits, "Who Filters the Filters: Understanding the Growth, Usefulness and Efficiency of Crowdsourced Ad Blocking," Oct. 2018, Available: https://arxiv.org/abs/1810.09160

[12] S. S. Hashmi, M. Ikram, and M. A. Kaafar, "A Longitudinal Analysis of Online Ad-Blocking Blacklists," Proceedings of the 44th IEEE Conference on Local Computer Networks (LCN), pp. 1-9, 2019. Available: https://arxiv.org/abs/1906.00166

[13] M. I. Bin Samsuddin, M. Y. Darus, S. J. Elias, A. H. M. Taib, N. Awang, and R. Din, "The evaluation of AdBlock technique implementation for enterprise network environment," Indones. J. Electr. Eng. Comput. Sci., vol. 13, no. 3, pp. 1102-1109, Mar. 2019. Available: https://doi.org/10.11591/ijeecs.v13.i3.pp1102-1109

[14] B. R. Gordon, K. Jerath, Z. Katona, S. Narayanan, J. Shin, and K. C. Wilbur, "Inefficiencies in Digital Advertising Markets," SSRN Electron. J., pp. 1-48, Sep. 2019, Available: https://doi.org/10.2139/ssrn.3459199

[15] U. Iqbal, P. Snyder, S. Zhu, B. Livshits, Z. Qian, and Z. Shafiq, “AdGraph: A Graph-Based Approach to Ad and Tracker Blocking," Proceedings of the IEEE Symposium on Security and Privacy, pp. 1-14, 2020. Available: https://umariqbal.com/papers/adgraph-sp2020.pdf

[16] R. J. Walls, E. D. Kilmer, N. Lageman, and P. D. McDaniel, "Measuring the Impact and Perception of Acceptable Advertisements," Proceedings of the 2015 ACM Conference on Internet Measurement Conference - IMC '15, pp. 107-120, 2015. Available: https://doi.org/10.1145/2815675.2815703 
[17] A. A. Tudoran, "Why do internet consumers block ads? New evidence from consumer opinion mining and sentiment analysis," Internet Res., vol. 29, no. 1, pp. 144-166, Feb. 2019. Available: https://doi.org/10.1108/IntR-06-2017-0221

[18] I. Redondo and G. Aznar, "To use or not to use ad blockers? The roles of knowledge of ad blockers and attitude toward online advertising," Telemat. Informatics, vol. 35, no. 6, pp. 1607-1616, 2018. Available: https://doi.org/10.1016/j.tele.2018.04.008

[19] H. Haddadi, R. Nithyanand, S. Khattak, and M. Javed, “The Adblocking Tug-of-War,” ;Login:, vol. 41, no. 4, pp. 41-43, 2016. Available: https://www.usenix.org/publications/login/winter2016/haddadi

[20] U. Iqbal, Z. Shafiq, and Z. Qian, "The Ad Wars: Retrospective Measurement and Analysis of Anti-Adblock Filter Lists Umar," Proceedings of the 2017 Internet Measurement Conference on - IMC '17, vol. 13, pp. 171183, 2017. Available: https://doi.org/10.1145/3131365.3131387

[21] J. L. Hemmer, "The Internet Advertising Battle: Copyright Laws Used to Stop the Use of Ad- Blocking Software,” Temple J. Sci. Technol. Environ. Law, vol. 1, pp. 479-497, 2005.

[22] J. Vallade, “Adblock plus and the Legal Implications of Online Commercial-Skipping," Rutgers Law Rev., vol. 7, pp. 823-853, 2009, Available: http://www.rutgerslawreview.com/wpcontent/uploads/archive/vol61/Issue3/Vallade_v61n3.pdf

[23] D. Moro, F. Benati, M. Mangili, and A. Capone, "Catching free-riders: in-network adblock detection with machine learning techniques," Proceedings of the IEEE 23rd International Workshop on Computer Aided Modeling and Design of Communication Links and Networks (CAMAD), pp. 1-6, 2018. Available: https://doi.org/10.1109/CAMAD.2018.8514955

[24] B. Esfandiari and R. Nock, "Adaptive filtering of advertisements on web pages," Special interest tracks and posters of the 14th international conference on World Wide Web - WWW '05, p. 916, 2005. Available: https://doi.org/10.1145/1062745.1062796

[25] J. Sandvig, D. Bajwa, and S. Ross, "Usage and Perceptions of Internet Ad Blockers: an exploratory study," Issues Inf. Syst., vol. XII, no. 1, pp. 59-69, 2011. Available: http://iacis.org/iis/2011/59-69_AL2011_1603.pdf

[26] A. K. Singh and V. Potdar, "Blocking online advertising - A state of the art," Proceedings of the 2009 IEEE International Conference on Industrial Technology, pp. 1-10, $2009 . \quad$ Available: https://doi.org/10.1109/ICIT.2009.4939739

[27] E. Pujol, O. Hohlfeld, and A. Feldmann, "Annoyed Users: Ads and Ad-Block Usage in the Wild," Proceedings of the 2015 ACM Conference on Internet Measurement Conference - IMC '15, pp. 93-106, 2015. Available: https://doi.org/10.1145/2815675.2815705

[28] W. W. Li, W. Hui, A. C. M. Leung, and W. T. Yue, "Content Restrictions on AdBlock Usage," Proceedings of the 21th Pacific Asia Conference on Information Systems, PACIS 2017, 2017, p. 84, Available: https://aisel.aisnet.org/pacis2017/84/

[29] M. H. Mughees, Z. Qian, and Z. Shafiq, "Detecting Anti Ad-blockers in the Wild," Proc. Priv. Enhancing Technol., vol. 2017, no. 3, pp. 130-146, 2017. Available: https://doi.org/10.1515/popets-2017-0032

[30] S. Zhu, X. Hu, Z. Qian, Z. Shafiq, and H. Yin, "Measuring and Disrupting Anti-Adblockers Using Differential Execution Analysis," Proceedings 2018 Network and Distributed System Security Symposium, pp. 1-15, 2018. Available: https://doi.org/10.14722/ndss.2018.23331

[31] A. Miklosik, M. Kuchta, and S. Zak, "Monetising Content Through Delivery of Advertisements: The Case of Ad Blockers," Ad Alta-Journal Interdiscip. Res., vol. 8, no. 1, pp. 175-179, 2018.

[32] M. A. Bashir, S. Arshad, E. Kirda, W. Robertson, and C. Wilson, "How Tracking Companies Circumvented Ad Blockers Using WebSockets," Proceedings of the Internet Measurement Conference 2018 - IMC '18, pp. 471-477, 2018. Available: https://doi.org/10.1145/3278532.3278573

[33] J. Söllner and F. Dost, "Exploring the Selective Use of Ad Blockers and Testing Banner Appeals to Reduce Ad Blocking," J. Advert., vol. 48, no. 3, pp. 302-312, May 2019. Available: https://doi.org/10.1080/00913367.2019.1613699

[34] D. Belanche, "Ethical limits to the intrusiveness of online advertising formats: A critical review of Better Ads Standards," J. Mark. Commun., vol. 25, no. 7, pp. 685-701, Oct. 2019. Available: https://doi.org/10.1080/13527266.2018.1562485

[35] A. Gervais, A. Filios, V. Lenders, and S. Capkun, "Quantifying Web Adblocker Privacy," Lecture Notes in Computer Science, S. Foley, D. Gollmann, and E. Snekkenes, Eds. vol. 10493, Springer, pp. 21-42, 2017. Available: https://doi.org/10.1007/978-3-319-66399-9_2 
[36] D. Ajdari, C. Hoofnagle, T. Stocksdale, and N. Good, "Web Privacy Tools and Their Effect on Tracking and User Experience on the $2013 . \quad$ Available: https://www.truststc.org/education/reu/13/Papers/AjdariD_StocksdaleT_Paper.pdf

[37] C. E. Wills and D. C. Uzunoglu, "What Ad Blockers Are (and Are Not) Doing," Proceedings of the 2016 Fourth IEEE Workshop on Hot Topics in Web Systems and Technologies (HotWeb), pp. 72-77, 2016. Available: https://doi.org/10.1109/HotWeb.2016.21

[38] A. Ray, H. Ghasemkhani, and K. Kannan, "Ad-Blockers, Advertisers and Internet: The Economic Implications of Ad-Blocker Platforms," Proceedings of the ICIS 2017: Transforming Society with Digital Innovation, pp. 110, 2018. Available: https://aisel.aisnet.org/icis2017/EBusiness/Presentations/15/

[39] D. Sánchez and A. Viejo, "Privacy-preserving and advertising-friendly web surfing," Comput. Commun., vol. 130, pp. 113-123, 2018. Available: https://doi.org/10.1016/j.comcom.2018.09.002

[40] B. Miroglio, D. Zeber, J. Kaye, and R. Weiss, "The Effect of Ad Blocking on User Engagement with the Web," Proceedings of the 2018 World Wide Web Conference on World Wide Web - WWW'18, pp. 813-821, 2018. Available: https://doi.org/10.1145/3178876.3186162

[41] J. Wielki and J. Grabara, "The impact of Ad-blocking on the sustainable development of the digital advertising ecosystem," Sustain., vol. 10, no. 11, pp. 1-14, 2018. Available: https://doi.org/10.3390/su10114039

[42] E. Abramek, A. Sołtysik-Piorunkiewicz and A. Strzelecki, "Technical and Social Reasons for Blocking Web Advertising in the Context of Sustainable Development of E-Business", Joint Proceedings of the BIR 2019 Workshops and Doctoral Consortium, (BIR-WS 2019), Eds.: R. Matulevičius, R. Buchmann, V. Řepa, M. Kirikova, K. Sandkuhl, M. Pańkowska, CEUR-WS, vol. 2443, pp. 39-50, 2019. Available: http://ceurws.org/Vol-2443/paper04.pdf

[43] S. S. Hashmi, M. Ikram, and S. Smith, "On Optimization of Ad-blocking Lists for Mobile Devices," Proceedings of MobiQuitous 2019 - 16th EAI International Conference on Mobile and Ubiquitous Systems: Computing, Networking and Services, pp. 1-8, 2019.

[44] C. Drazner, N. Đuza, H. Jonker, and D. S. Wallach, "Investigating the effectiveness of web adblockers." pp. 17, 12-Dec-2019. Available: https://arxiv.org/abs/1912.06176

[45] S. L. Wang, Y. T. Hou, and S. Kankham, "Behavior modality of Internet technology on reliability analysis and trust perception for international purchase behavior," Symmetry, vol. 11, no. 8, 2019. Available: https://doi.org/10.3390/sym11080989 